\title{
A Business Model for Hydrogen Fuel and Hydrogen Cars Infrastructure
}

\section{Mordechai Ben-Menachem ${ }^{\star}$}

Yeshiva Kever Rachel, Bethlehem, Israel

\begin{abstract}
It is clear to any objective observer that in the coming decades - likely by the year 2050 - the use of hydrogen for energy will be a central global phenomenon - facts on the ground demand it, facts under the ground demand it and consumers demand it (the latter being the most important). When a Business Model is driven by consumer demand, the products, as well as the model, must be as responsive as those consumers expect.

Hydrogen will be increasingly needed for automobiles, and this is probably the largest application in terms of quantity of gas used, but it is also sorely needed for many other applications; industrial but not only large-scale industrial (the coming decades will also see a large increase in individual manufacturing via printing technologies, as well as greater emphasis on nanotechnologies, and hydrogen is also very important to both of those).

However, there are two impediments which must be addressed: scaling up and Green Hydrogen (or at least, significantly "greener") both of those terms are described below.

This article addresses these two central issues, as well as other less central, issues needed to support that effort. The project herein described is an actual project (not theoretical) in process of being built. Caveat: Specific Product names are not used to prevent ethical violations.
\end{abstract}

Keywords: Hydrogen; Storage tanks; Vehicular hacking; Water electrolysis; Anaerobic digestion; Waste management; Lithium

\section{Introduction}

"The final goal, if you want to be CO2 emission-free, is to produce hydrogen from sources that do not produce CO2" - Giorgio Zoia, Toyota 2017.

Nearly ALL hydrogen produced today in the world is produced by electricity from a national grid, in other words, the hydrogen production process expels large amounts of $\mathrm{CO}_{2}$. This is classed as "Brown Hydrogen" and is considered significantly of less value than hydrogen produced in a manner which is carbon neutral. Remember what is stated above in the abstract, consumers are driving this market at least as much as are engineering and scientific (i.e., product) needs. Consumers are increasingly demanding Green or Greener hydrogen. If there were no practical way to attain this, one could state that this issue is of no or lesser importance. However, the point of this article is to show that this is NOT the case and that Green Hydrogen can be produced, efficiently, practically and inexpensively, and this Green Hydrogen can be used for the entire hydrogen fuel infrastructure. However, creativity of thought is required. The entire business model must be designed from inception for these goals. There are logistical complexities that need to be addressed intelligently for this system to function economically and practically. In any case, when these logistical exigencies are well-addressed, the business benefits are far more than 'only' economic, and the financial benefits are as large as the market; as is shown below [1-35].

\section{Alternative energy exigencies}

Hydrogen energy is known as one of many energy sources that are called 'alternative' because 'main stream' energy is generally from fossil fuels - petroleum, natural gas and/or coal. We need to be clear on this appellation. Fossil fuels are mined from the earth. There are myriad problems with this, including geopolitical issues, as well as engineering issues; but no matter how many problems that exist with this source of fuel, humanity has been using them for thousands of years and all of the processes that surround them (e.g., search and exploration, mining/ pumping, transporting and etc.) are honed and highly efficient. Hence, fossil fuels, even when pressured artificially with political limitations (such as cartels) are fantastically cheap (we disregard here issues of "fair pricing" - fairness is neither a political nor an engineering term). In parallel with this cost however, fossil fuels are also very dirty in both transportations and usage. Tens of thousands (some sources say, millions) of people sicken and die every year from air, water and ground pollution resulting from fossil fuels $[19,24]$. Their cost, plentiful distribution and high energy content mean they are not going away in the foreseeable future, if ever. Many attempts have been made to make a case that there just are not sufficient quantities [8], but reality has proven this to be simply not the case.

Withal, and as a result of the costs/benefits of fossil fuels AND alternative fuels, it has become increasing imperative for countries to have at their command a reasonable level of energy security, as a basic component of national security [5,9]. Energy security today means also a certain level of technology, within their culture. In other words, a country that does not command its energy security does not command its future.

All "alternative energy" sources are good and beneficial, but all have limitations, and most of these limitations are generally unknown. Fossil fuels also have limitations. However, the difference is, as stated above, that humanity has been utilising fossil fuels for thousands of years and these limitation have been addressed - we are collectively used to them.

*Corresponding author: Mordechai Ben-Menachem, Yeshiva Kever Rachel, Bethlehem, Israel, Tel: 0552259763; E-mail: qualitymbm@gmail.com

Received January 22, 2018; Accepted January 29, 2018; Published February 03, 2018

Citation: Ben-Menachem M (2018) A Business Model for Hydrogen Fuel and Hydrogen Cars Infrastructure. J Bus Fin Aff 7: 313. doi: 10.4172/21670234.1000313

Copyright: (c) 2018 Ben-Menachem M. This is an open-access article distributed under the terms of the Creative Commons Attribution License, which permits unrestricted use, distribution, and reproduction in any medium, provided the original author and source are credited. 
What that means is that fossil fuels are still being used, and will remain so, but are being augmented by alternative sources of energy [30]. As the sage said, anything done in excess has danger; fossil fuels must be augmented, but the objective need not be total replacement, at this time.

\section{Nuclear}

The first major national/utility-level attempt at an alternative energy source was nuclear. This was post-World War II. The attempt to utilise nuclear reactors for industrial and energy was quite early in the nuclear industry's development. Unfortunately, the nuclear industry has not, to put it mildly, proven its long-term worth to humanity.

As an example of these difficulties, Mr. Obama promised as part of his electioneering platform in 2008 to significantly enhance the nuclear industry in the United States as a long-term replacement for fossil fuels, and particularly coal. Instead of that, he closed the Yucca Mountain Nuclear Waste storage site and five nuclear-powered electricity generating plants were shuttered during his eight-year tenure, while not a single new nuclear plant came on line or was even fully approved.

This highlights two critical issues concerning nuclear energy: A) it creates nuclear waste that is exceedingly difficult and dangerous to control and dispose of safely; and B) alongside a horrible safety reputation in the eyes of the public (which is not totally deserved, though not totally undeserved) the time to register, regulate, build and bring on-line new nuclear-energy electricity plants is exceedingly long, as well as being highly cost prohibitive [12]. Many countries have lately begun processes of nuclear installations. In most cases, this is more an issue of national pride, then actual economic sanity.

China for instance, is in process of building a very large number of nuclear energy plants. If one calculates the number of existing nuclear plants and the number of new nuclear plants being built, throughout the world today, and then compares this with known uranium deposits one quite quickly sees that the planet simply does not possess a sufficient quantity of uranium for all those plants - even with massive retirement of nuclear plants in Germany and Japan following disasters.

Approving new ones is, at best, a very expensive exercise in futility, if not hubris and folly.

\section{Solar}

Solar energy sourcing has two types; photovoltaic (PV) and thermal energy $[12,13,20]$. Both of these energy sources have numerous benefits, but also contain within them numerous problems. Some of these problems can eventually be solved with time, but some of them can never be solved [24].

Solar energy is a superb energy source for many niche applications, and can even be a good source, in certain locales, for general energy needs. However, one needs to be aware that solar energy availability (insolation) does not depend upon how warm a climate is, but only upon availability of direct sunlight [13]. As an example, the nation of Cameroons has a warm climate, but it also has a high level of cloud cover, meaning that the total yearly average insolation at the capitol city is only 4.99 hours per day, making it of borderline value for solar installations. Belize also has only 4.81; Bolivia 3.94; Columbia 3.78; Quito Ecuador has 3.75. These are all countries that are thought of as warm climes. Of course, massive installation of solar in place with cold climes, such as Germany (insolation of 2.98 in Munich) is simply hubris.

Note that all this does not differentiate between thermal and PV, because what really matters here is the total amount of solar energy the sun places at the disposal of these geographies. The comment is neither 'political' nor biased in any other way - it is observational, quantitative science. If the application needs are minimal, one can simply place another collector panel - if the space permits. In a country like Zimbabwe, for instance, which is land-locked and has limited access to fossil fuels, of Tahiti (Puerto Rico and other island nations) that have 'easy access' but fossil fuels' transport is very costly and prohibitive (and polluting) solar can be a viable option. But Utility-level solar, whether PV or thermal, needs to be given careful consideration; it should NEVER be considered as the 'only' viable option and clearly sought. Entire life-cycle costs are a minimal, but insufficient consideration [12]

Furthermore, solar has two additional problems. The first is directly related to the issue of insolation. The sun provides a given, and constant, amount of energy at every geographical location - "X energy per square metre of space on the planet surface". As we saw above, this total sunlight does not always reach the planetary surface. Solar panels have an engineering limitation. The finest solar panels have, at time of manufacture, a collection efficiency of about $20 \%$ of the total energy that actually reaches the panel (collection efficiency wears down with age and can reach fifty percent of what it was when new) this consideration is in addition to dust collection which can chop another 20-25\% off the collection capacity, if the panels are not well maintained.

In theory, the PV collection capacity should continue to rise as companies' R\&D efforts improve capabilities but, until it rises quite significantly, by at least half, to $30 \%$, the amount of surface area needed for solar power is inhibitive. Real estate, even in the 'worst' places, is costly. The second problem is fascinating, mostly because it has been hidden from public awareness intentionally. The energy-cost of solar panel manufacture, from silicon until a working product, is higher than the total amount of energy the panel will produce during its life expectancy. In other words, at a national-grid/utility-level, solar PV can never be a viable solution, except in very limited cases, and even in those cases, this is at the expense of the planet, as a whole.

Interestingly, solar thermal has about the same efficiency. Data are not available, at this time, to estimate the energy-cost of their manufacture, though solar thermal, when adequately maintained, does not wear out over time as does PV. In balance though, it has additional problems that PV does not, which tend to be beyond the scope of this paper.

\section{Hydrogen as a Clean Energy Source}

Hydrogen is the fuel of the sun - as far as we are presently aware, it is the fuel of all stars. Stars use nuclear fusion for their energy. Nobody today suggests nuclear fusion will be a viable, on-planet, energy source within the coming decades. The energy sourced from hydrogen is derived by combining hydrogen with oxygen, in a controlled manner (in other words, a chemical, not a nuclear, reaction). This may be via "Fuel Cells" or via direct "burning" to combine the hydrogen with oxygen [17]. This produces water $\left(\mathrm{H}_{2} \mathrm{O}\right)$ and has no pollutants, of any kind. However, and this is a critical issue, a large quantity of pollutants can be created by the manufacture of hydrogen, prerequisite to this.

1. Hydrogen 'types' by source BROWN H2 - Made from nonrenewable energy (e.g., direct from existing national grid) - $\mathrm{H} 2$ production technology not pure.

2. GRAY H2 (BLUE H2) - Similar to Brown but slight improvements (e.g., some pro-portion from solar).

3. GREEN H2 - Clean, totally renewable energy, $\mathrm{H} 2$ produced 
from pure water, with no carbon released to the atmosphere during the production of the energy used for the hydrogen production.

4. Hydrogen uses today: Electronics, Electricity, Oil and Gas, Chemistry, Welding, Fuel for Cars, Trucks, Busses and Trains, Metallurgy, Thermonuclear and Manufacturing.

The usual method of hydrogen manufacture, is water electrolysis; breaking it into hydrogen and oxygen. If the hydrogen is manufactured by electrolysis fuelled off the national grid, the grid demand produces the hydrogen while also generating very large quantities of carbon released supposed into the atmosphere (in the form of carbon dioxide). This is called "brown hydrogen" (see the side bar).

Generally, certainly in nature, more energy is needed to break water than to combine. That is why, for this project, many differing manufacturing techniques and technologies were exhaustively studied $[7,14,15,22,23]$.

In other words, if we wish to create hydrogen efficiently and without release of carbon di-oxide, we need to both create the electricity in a carbon neutral manner and use the most efficient hydrogen-production methods (equipment) available, while constantly researching possibilities of enhancing that efficiency. (As no technology is ever 'perfect', and this issue has 'anti-pollution' as a major factor, constant improvement is an imperative, and not an option.)

As our largest application is automobiles, as stated above, the objective is totally emission-free automobiles.

Can hydrogen be produced by purely solar PV means? The answer is yes, but we have seen that PV is problematical [14]. In the vast majority of venues (few people live in the Sahara desert, while many people live in the Boston-Washington corridor) this is highly impractical. If nothing else, this underutilises ground better used to produce food for these people. Something significantly better must be used.

\section{The Project Model}

The model used by this research begins with collection of dry organic waste matter. This is the logistical challenge mentioned above. The most energy-efficient types of dry organics are used tyres, plastics and creosoted wood. Efficient collection and transport of these materials is a significant limiting factor. (Transportation can be energy profligate, with efficiencies generally decaying as distances grow.) All of these are bulky and heavy. They need to be pre-treated for usel pretreatment usually consists mostly of granularization (cutting them into pieces that can be efficiently handled).

The following step is Thermal Conversion of Organic Matter (e.g., waste) to clean Electric Power. Generally there are three types of waste: A) inert (e.g., glass, metals and ceramics), B) Dry Organic and C) Wet Organic. The first type has no available energy content and hence, is not relevant to this application, at this time. The most energy-valuable materials are, as listed above, tyres, plastics and creosoted wood, which are dry organic. Our productivity estimation is about three barrels of petroleum equivalent for every ton of tyres. Of course, all output equivalences depend upon precise inputs, so exact estimations are not possible in the confines of a paper such as this. The planned processing rate of this project, when fully implemented, is fourteen tons of input per hour, 24/7/360.

Wet organic materials are many and varied. The following are the most common:
- $\quad$ Food waste, Sewage sludge (wastewater treatment plants' by-product that go to a landfill), Manure, Biomass (e.g., tree and grass clippings), Agricultural (e.g., nut shells, corn cobs and other crop waste), Forestry waste (e.g., lumber, bark, trees). These are a second, lower, priority (after dry organic) as they need first to be dried before efficient utilisation. Municipal solid wastes (e.g., residential, commercial and industrial trash) are a third (lowest) priority, as they need to be both sorted and dried before use.

- All wet organic material, both those listed here as priority two and three, would be used after anaerobic digestion treatment has produced bio-methane. These then need to be dried for utilisation by the Thermal conversion process, while the bio-methane can be used as fuel, in parallel. However, anaerobic digestion is not, at this time, part of the project herein described, though it will be at a later time, and in a different venue.

- The conversion process turns these solids into a gas called syngas, a liquid called syn-diesel and carbon bi-products. The syngas and the syn-diesel are directly used for energy production - in this case, for production of electricity. However, the production of this electricity is carbon neutral because the carbon embedded in the baseproducts (e.g., the tyres) is completely captured and reused and none is released into the atmosphere. (Note that any release of materials into the atmosphere is economically inefficient and would cause the entire system to be non-profitable, and hence, must be avoided assiduously.)

- The carbon bi-products of the System include activated carbon, bio-char and other high energy solid carbons. Combined, these various forms capture all carbon produced from the organic-materials' conversion. In other words, all carbon is captured and sequestered for reuse. The bio-char and activated carbon produced are products themselves and are part of the project profit-computation. Bio-char is a valuable component of fertilisers and other products (fertilisers are products). Activated carbon is used in filtrations systems and many other applications.

\section{The Process}

The process designed for this system has been designed from the beginning for "infinite" (unlimited) scale-up. This is critical because for this to be a viable solution, particularly for the automotive market, it must be capable of making hydrogen fuel available anywhere in the world, 24/7/365. "Scale-up," in this context, refers to both installation size and locale. That is a minimal criterion.

Additionally, bio-fuels created (syngas and syn-diesel) can be further refined to produce higher grades of synthetic fuels (when not used for hydrogen production or other electric needs)

The conversion technology is backed by over thirty years of research and development in state-of-the-art energy technology labs and fullsized operations. It is a system that consists of twenty-seven fully tested and proven, patented solutions to reducing waste and carbon emissions, in a proprietary pyrolytic process, relying on controlled gasification, under pressure, dramatically increasing carbonization speed and quality over other processes; resulting in biomass conversion into carbon in thirty to forty minutes, and with $200 \%$ more energy value than current commercial technologies (Figure 1).

This SYNDIESEL has 50\% higher energy than fossil fuel diesel - CETANE rating 60 VS. fossil fuels' 40 - thus, increasing both efficiency and output. The system then produces electric power from the SYNDIESEL produced by the pyrolysis subsystem. The 25-35 


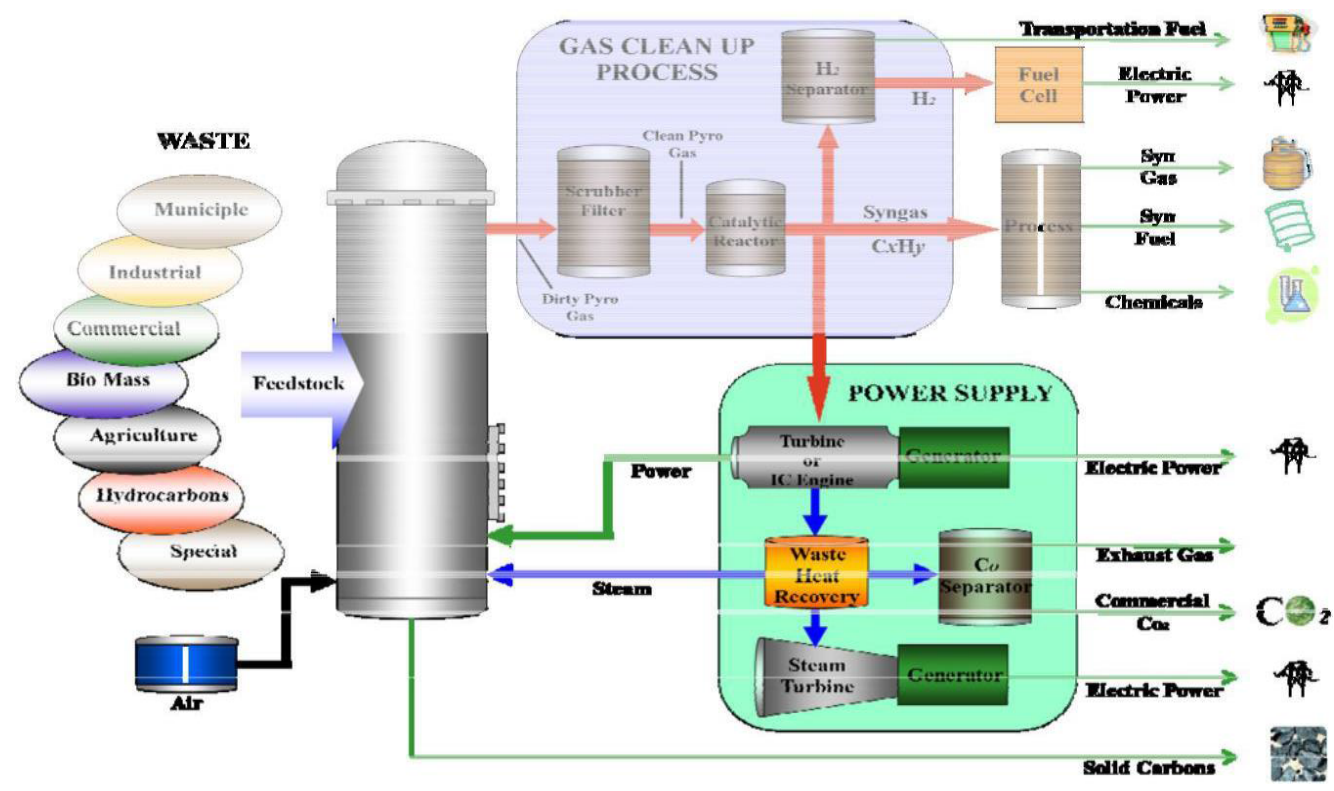

Figure 1: Typical thermal conversion system.

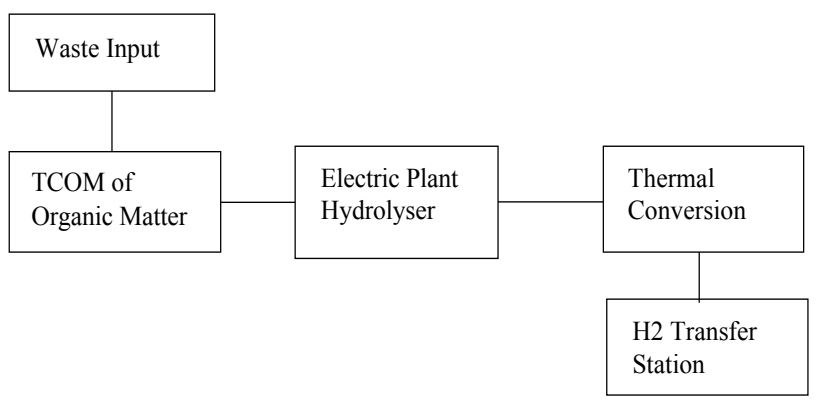

Figure 2: H2 production system overview.

MEGAWATTs power the HYDROLYSER and the excess runs the remainder of the facility. By using totally "Green fuel" for all generating equipment and an advanced Hydrolyser producing pure hydrogen, the hydrogen provided will be of the highest quality and free from contaminants, while also avoiding all environmental impacts.

Our plan is to purchase and install a large number of generators to provide power $24 / 7 / 365$, running continuously with multiple backups and "infinite" redundancy. Thus, maintenance is no longer an issue and catastrophic breakdown becomes a near impossibility.

In any case, safety and system security have also been given high priorities [4]. However, explicit description of these methods and cose are out of scope of this paper - and public revelation of the terms and methods used would tend to be counter-productive (Figure 2).

\section{Hydrogen - the end product}

As stated, the hydrogen produced by this project is primarily intended for use by automobiles [1] and other motorized vehicles, such as military vehicles and airplanes $[17,21]$. That is the main reason why the purity of both the end product and the processes to produce that end-product are imperative. Nothing can be allowed to compromise this state of purity - product and process.
As a side note, the electrolysis process that breaks down water, of course, produces oxygen, as well [7,22]. However, at this time, the oxygen produced is not intended to be captured for use or sale as that adds an additional complexity that is unnecessary for project profitability.

Power demands grow constantly and steadily, both in developed and in less developed countries, all over the world. This growing power demand, coupled with global interest in $\mathrm{CO}_{2}$ emissions reduction, stimulates renewable energy sources implementation [22]. With this, intermittent power disruptions are common in renewable energy sources (wind does not blow equally, all day, every day; the sun does not shine at night). Hydrogen also utilises stored energy for when needed most $[16,23]$.

Hydrogen Fuelling: fuel-cell powered vehicles are becoming increasingly more prevalent among consumers; both private automobiles and commercial vehicles $[1,27]$. There is a sore lack however, in fuelling infrastructure for these vehicles, which is what this project addresses. This lack of widely-available infrastructure has emphasised the elevated demand for hydrogen fuel. Converting energy from renewable sources into hydrogen via polymer electrolyte membrane (PEM) water electrolysis, on-site gas generators produce green hydrogen to drive carbon-free emission objectives.

It is important to note that, while PV decreases in production capacity with age, the polymer electrolyte membrane electrolysis process (PEM) does not (Table 1) [29,35].

\section{Future power}

Asking Google: "What percentage of potential energy in petrol is actually used” Elicits four million responses: “HUH!?”

The US Department of Energy together with California Energy Commission publishes a site with consumer "advice" where they supply some quantification of energy density for automobiles [3134]. They claim that about fifteen percent of the energy poured into the automobile actually is used and the remainder is inefficiencies. 


\begin{tabular}{|c|c|c|c|c|c|c|}
\hline & \multicolumn{2}{|c|}{ Weight } & \multicolumn{2}{|c|}{ Gas } & \multicolumn{2}{|c|}{ Liquid } \\
\hline & Pounds (Ib) & Kilograms (kg) & Cubic feet (cf) & cu meters (m3) & Gallons (gal) & Litres (I) \\
\hline 1 Pound & 1.0 & 0.4536 & 192.0 & 5.047 & 1.6928 & 6.408 \\
\hline 1 Kilogram & 2.205 & 1.0 & 423.3 & 11.126 & 3.377 & 14.13 \\
\hline $1 \mathrm{cf}$ gas & 0.00521 & 0.00236 & 1.0 & 0.02628 & 0.00882 & 0.033 \\
\hline $1 \mathrm{~m} 3$ gas & 0.19815 & 0.08988 & 38.04 & 1.0 & 0.3355 & 1.27 \\
\hline 1 Gallon liquid & 0.5906 & 0.2679 & 113.4 & 2.981 & 1.0 & 3.785 \\
\hline 1 Litre liquid & 0.15604 & 0.07078 & 29.99 & 0.7881 & 0.2642 & 1.0 \\
\hline
\end{tabular}

Table 1: Unit conversion data for hydrogen.

[Consumer Tips; "Energy Losses in a Vehicle" [6]]. This includes some sixty-two percent lost in the engine. The US Department of Energy puts this number at fourteen percent - the difference is statistically insignificant.

The equivalent US DoE site for Diesel claims that diesel fuel contains a higher energy content but provides no number-guidance as to fuel efficiency or energy density. [US Department of Energy [33]; "Where the Energy Goes: Gasoline Vehicles", US Department of Energy [32]; "Diesel Vehicles"] On Hybrids, the equivalent US Government site claims twenty-five to forty percent (25-40\%) fuel efficiency. [US Department of Energy [33]; "Where the Energy Goes: Hybrids"]. While finally the US Government equivalent site for all electric vehicles claims that seventy-four to ninety-four percent of the fuel is used to move the car. [US Department of Energy [34]; "Where the Energy Goes: Hybrids"]. All things considered, the US Government's "political" agenda seems more to be advanced here than science.

Why do I say that? Why do I doubt this source?

If all-electric cars where so super-efficient, I believe we would see highly successful products. So far, the best that can be said for all-electric automobiles is that they may be reasonable for some niche applications, but they are still far from viable for the vast majority of consumers [11].

\section{Future vehicles}

Are we headed towards a world where individual mobility will be based upon all electric vehicles? Firstly, supplying electricity via the national grids for a vast armada of electric vehicles is not practical the capacity does not exist and to make it exist, is both improbable and highly cost-ineffective (as well as highly polluting). So far, electric vehicles are based upon lithium-based batteries. Lithium is in constant short supply. Battery technology advances at a rate of about six percent per year. At that rate, several decades more are needed before the allelectric vehicle may become a viable universal product. Simply put, this is too long to wait, for a highly questionable product, with limited applicability.

Science Fiction: It is well-known that science fiction writers provide a vast source of inspiration for engineering advances. What may we learn from Science Fiction towards mobile fighting vehicles? There have been three military science fiction series that came out on-screen, relevant to our subject. There have been no exceptional military science fiction books (at least, not for a very long time). Star Trek and Star Gate (regardless of any opinion as to the various qualities) were space-based and ground based military, but all ground based action was based upon highly trained, special forces. Hence, for our purposes here, they are not helpful.

The first Star Wars movies were introduced in 1977 - half a century ago, with the second series of movies beginning in 1999. In this second series, the so-called "prequel," that we saw a vision of groundbased military action, that also used motorised vehicles. Considered observation of these "suggestions" indicates that they are all possible, but are today blocked by our continued dependence upon ridiculously inefficient internal combustion engines. It is clear that petrol-based fuel is an excellent fuel source; but it is also clear that the internal combustion engine is a dead end that has reached, or very nearly reached, its efficiency apogee; despite excellent attempts to alleviate the absurdity of inefficiency that exists today [9].

What is likely to be the direction for the "new engine" that we may attempt to imagine here? Clearly, this is speculative. My personal experience indicates that whatever any one of us expects, someone will surprise us with a direction that was less expected [Dyke; "Powering a green car revolution, Israeli style" [10]].

(I have visited this company - Aquarius Engines - and their technology is amazing. Is it 'sufficient' to revolutionise all aspects of motorised vehicles as envisioned by this article? Quite certainly not! The inventor made it very clear that they are designed for a specific purpose and for that they are superbly suited. They are a significant step in making standard automobiles quite a lot better in terms of fuel efficiencies. Can they be engineered differently to suit them for other applications? That is quite unclear).

My personal view is that the most likely direction may be something like either a plasma-based engine or a pulse-ion-based engine, fuelled by fossil fuel - petrol (liquid fossil fuel). How likely is this? Nobody knows or can know. What we do know is there exists plenty of liquid fossil fuel, that it is fantastically rich in energy and that it is readily available - these liquids are definitely not about to give out! [Deffeyes: "When Oil Peaked" [8]].

\section{Hacking - the coffee shoppe metaphor}

A Mercedes travelling at high speed, crashed into a tree a few years ago, exploding into flames and killing the driver; the engine ejected 50 meters from the car. Was it an accident or was the car hacked, driving it off the road by remote control? It might sound like a movie, but the driver was identified as journalist Michael Hastings, who was known for revelations on US military and intelligence agencies. Hastings had emailed colleagues the day before saying he was going "off the radar for a bit" to chase down a "big story". Accident or intent - conspiracy theorists claim to know; I have no data [2].

In vehicles today - automobiles, military vehicles and airplanes it is important that all applications have strict security measures built into them $[18,26]$, with clear user identification; whether a consumer application or a manufacturer's. None of this security presently exists, for any commercial product. This means that a 'hacker' (any person skilled in software code encryption, decryption and manipulation) can devise a software application capable of identifying a specific person in a precise automobile, truck, airplane (etcetera) anywhere-anytime; even a Crown Prince.

The same, or a different person, may devise a 'Stuxnet-like' 
application that travels to that vehicle, identifies the target, and perhaps other passengers, and 'powers down' the car's or truck's braking system, or the ability to extend landing wheels, or simply takes over and heads for the nearest tree at full speed - or any of another hundred or so ways to make the vehicle into a death device.

All this can, of course, be done from the comfort of one's favourite armchair at home - or from an internet-linked Coffee Shoppe, anywhere, anytime [1].

Assassination can be prevented via building strong firewall protection around all com-link applications, but this defeats the download device to repair failures before they occur, at very considerable saving of consumer lives and cost savings to manufacturers - a fascinating dichotomy between abilities and requirements.

This capability is a new kind of gun and we need to enhance awareness of the possibilities. Who is responsible for ensuring security of vehicles - cars, trucks, airplanes and etcetera? Interestingly, in an analysis of DHS budget reports from the past five years, exactly zero dollars have been allocated to this issue.

For perspective: engineers Javier Vázquez Vidal and Alberto Garcia Illera built a $\$ 25$ device to bypass automobile electronic control unit security; and a wireless version is on the way or already functional. This is one effort of the kind, of many. So for private automobiles...

What is the relevance of this conundrum to hydrogen? Petrolbased automobiles, when used in such a manner, may explode upon impact (certainly every "adventure movie" knows this, as part of their "special effects" trope). Such an automobile powered by hydrogen is much, much scarier than the equivalent powered by petrol. Hence, it is the contention of this article that viable hydrogen-based automobiles must enhance their emphasis on both safety and security. This is not an option. It is imperative for product success - remember once again that this is a consumer-driven market.

\section{Conclusion}

To put this entire issue into perspective: the project herein described is in advanced design stages of the site and logistics - all technical designs are complete. A new level of thinking is needed and a new way of thinking about powering large, heavy vehicles must be invented. The project produces green clean hydrogen, in a carbon neutral manner. One hundred percent green clean pure hydrogen gas.

In addition, it also reduces trash in landfills - almost all urban landfills throughout the world are nearing satiation. Reduction of volume to landfills is critical to many, if not almost all, cities throughout the world.

The system is completely repeatable and scalable, and ready for installation nearly anywhere in the world. At the same time, it is the first facility in the world to be able to make pure clean green hydrogen totally from waste.

\section{References}

1. Associated Press (2017) GM, Honda team up to develop advanced hydrogen fuel cells.

2. Ben-Menachem M (2010) Assassination Via Coffee Shoppe. Human Events and Bearing Arms.

3. Ben-Menachem M (2017) On Land Warfare and Motor Vehicles: From Biblica Times, Through Tomorrow. Journal of Defense Management 7: 156.

4. Bjerketvedt D, Mjaavatten A (2005) A Hydrogen-Air Explosion in a Process Plant: A Case History. 5th international conference, Norway.
5. Bryen SD (2016) Technology Security and National Power: Winners and Losers. Transaction Publishers, pp: 327.

6. Consumer Tips (2016) Energy Losses in a Vehicle: California Energy Commission.

7. David WIF, Makepeace JW, Callear SK, Hunter HMA, Taylor JD, et al. (2010) Hydrogen Production from Ammonia Using Sodium Amide. Journal of the American Chemical Society 136: 13082-13085.

8. Deffeyes KS (2010) When Oil Peaked. Hill and Wang.

9. Delaney WP, Atkins RG, Bernard AD, Boroson DM, Ebel DJ (2015) Perspectives on Defense Systems Analysis. MIT Lincoln Laboratory Series, MIT Press.

10. Dyke J (2016) Powering a green car revolution, Israeli style. The Times of Israel.

11. Economist editorial (2016) A Plug for the Battery Economist.

12. EIA (2016) Capital Cost Estimates for Utility Scale Electricity Generating Plants. Energy Information Agency, Independent Statistics \& Analysis, USA.

13. Evseev EG, Kudish Al (2015) Analysis of solar irradiation measurements at Beer Sheva, Israel from 1985 through 2013. Energy Conversion and Management.

14. Florida Solar Energy Center (2017) Hydrogen Basics-Solar Production. Florida Solar Energy Center, USA

15. Gates B (2017) Beating Nature at Its Own Game. Co-chair, Bill \& Melinda Gates Foundation.

16. Hirtenstein A (2017) Big Energy Backs Hydrogen Power Storage.

17. i-HIS staff (2017) Fuel Cell Technology - What Benefits for Military Vehicles?

18. I-HLS (2017) Big Brother will shut down your car. I-HLs Homeland Security.

19. Charles K (2008) How pollution influences the weekend weather.

20. Karin K (2013) Bright Source takes solar thermal energy home to Israel.

21. Leichman AK (2017) Clean electric power for planes could be about to take off

22. Levene JI, Mann MK, Margolis R, Milbrandt A (2005) An Analysis of Hydrogen Production from Renewable Electricity Sources. National Renewable Energy Laboratory, USA.

23. Lipman T (2011) An Overview of Hydrogen Production and Storage Systems with renewable hydrogen case studies. Clean Energy States Alliance.

24. Bart M (2007) Sustainable Consumption: The Evolution of a Concept, two-part report on the emergence of sustainable consumption. Stratfor.

25. Ramez N (2015) Why Energy Storage is About to Get Big - and Cheap.

26. Papaws J (2011) Glitch: The Hidden Impact of Faulty Software. Prentice Hall.

27. Giles P (2013) The Long-Term Energy Storage Challenge: Batteries Not Included. GTM research, RenewEconomy.

28. Pipoli T (2005) Feasibility of Biomass-Based Fuel Cells for Manned Space Exploration. ESA-ESTEC Advanced Concepts Team, The Netherlands.

29. Jean-Pierre $P$, Capitaine A (2010) Hydrogen Production by High Temperature Electrolysis of Water Vapour and Nuclear Reactors.

30. SR/OIAF-CNEAF (2008) The Impact of Increased Use of Hydrogen on Petroleum Consumption and Carbon Dioxide Emissions. Energy Information Administration, USA.

31. US Department of Energy (2016) Where the Energy Goes: Gasoline Vehicles. US Government Department of Energy.

32. US Department of Energy (2016) Diesel Vehicles. US Government Department of Energy.

33. US Department of Energy (2016) Where the Energy Goes: Hybrids. US Government Department of Energy.

34. US Department of Energy (2016) Where the Energy Goes: Electric Cars. US Government Department of Energy.

35. Ryan W (2015) Stanford discovers cheap way to produce hydrogen 24/7. 